\title{
Complexity as a Guide to Understanding Decision Bias: A Contribution to the Favorite-Longshot Bias Debate ${ }^{\dagger}$
}

\author{
MING-CHIEN SUNG ${ }^{1}$, JOHNNIE ERIC VICTOR JOHNSON ${ }^{1 *}$ \\ and ITIEL E. DROR ${ }^{2}$ \\ ${ }^{1}$ Centre for Risk Research, School of Management, University of Southampton, UK \\ ${ }^{2}$ University College London, UK; and Cognitive Consultants International Ltd
}

\begin{abstract}
This paper investigates the origins of a widespread decision bias in betting markets, the favorite-longshot bias (FLB); in particular, whether it is caused by cognitive errors on the part of bettors or by the pricing policies of bookmakers. The methodology is based on previous literature, which has suggested that: (i) races, as decision tasks for bettors, can be distinguished by their degree of complexity and their attractiveness to those with access to privileged information (insiders), (ii) cognitive errors increase as complexity increases, and (iii) bookmakers set odds in a manner to protect themselves from insiders. The degree of FLB was examined in races of varying complexity and attractiveness to insiders using a dataset of 8545 races drawn from the parallel bookmaker and pari-mutuel markets operating in the UK in 2004. The results, interpreted in the light of the cognitive error and complexity literature, suggest that neither bettors' nor bookmakers' cognitive errors are the main cause of the bias. Rather, bettors' preferences for risk and the deliberate pricing policies of bookmakers play key roles in influencing the bias in markets where bookmakers and pari-mutuel operators coexist. Copyright (C) 2008 John Wiley \& Sons, Ltd.
\end{abstract}

KEY WORDS complexity; favorite-longshot bias; betting markets; probability judgments

\section{INTRODUCTION}

The favorite-longshot bias (FLB), whereby the prices of longshots and favorites tend to over and underestimate their respective chances of success, has been documented in horserace betting markets over many years, across a variety of countries and in different market forms (e.g., USA: Ali, 1977; Asch, Malkiel, \& Quandt, 1982; McGlothlin, 1956; Snowberg \& Wolfers, 2005; Snyder, 1978; Thaler \& Ziemba, 1988;

\footnotetext{
* Correspondence to: Johnnie Eric Victor Johnson, Centre for Risk Research, School of Management, University of Southampton, Southampton, UK. E-mail: jej@soton.ac.uk

${ }^{\dagger}$ We are grateful to Peter Ayton and the anonymous referees for their insightful comments on an earlier draft of this paper.
} 
Ziemba \& Hausch, 1986; Australia: Bird \& McRCrae, 1994; Tuckwell, 1983; New Zealand: Gander, Zuber, \& Johnson, 2001; van Zijl, 1984; UK: Bruce \& Johnson, 2000; Dowie, 1976; Sung \& Johnson, 2008; Vaughan Williams \& Paton, 1997). A range of explanations for the bias has been proposed, attributing its cause either to bettors' misperceptions, cognitive errors or preferences for risk, or to the rational decisions of market makers (bookmakers).

To date, the majority of studies reporting the FLB have been conducted in pari-mutuel markets, where odds are largely determined by the actions of bettors, and this prevents examination of the degree to which bookmakers influence the bias. One of the few papers to compare FLB in bookmaker and pari-mutuel markets (Bruce and Johnson, 2000) found a greater incidence of the bias in the former. This was taken as evidence that the actions of bookmakers are responsible for creating at least some of the bias. However, no direct evidence of their role in influencing the bias was provided nor did the paper examine the reasons why the FLB persists in pari-mutuel markets. In contrast, the current study explores to what extent the source of the bias can be attributed to the pricing policies of bookmakers or to bettors' cognitive errors.

The selection of the likely winner of a race can be regarded as a decision task, and we employ an established methodology to categorize races according to their degree of inherent alternative- and attributebased complexity (Johnson \& Bruce, 1998). Previous research suggests that decision makers' cognitive errors increase with alternative- and attribute-based complexity (e.g., Dror, Busemeyer, \& Basola, 1999; Kahneman, Slovic, \& Tversky, 1982; Malhotra, 1982; Paquette \& Kida, 1988). We examine the incidence of the FLB in the parallel pari-mutuel and bookmaker betting markets which operate in the UK and, if cognitive errors are an important source of the FLB, we expect the bias to be greatest for more complex races, particularly in the pari-mutuel market where the odds are determined solely by the actions of bettors. Those who attribute the FLB to the actions of bookmakers suggest that it results from their defensive pricing against the actions of those bettors with access to privileged information ("insiders," such as owners and trainers) (e.g., Shin, 1992). We will argue that certain types of race are more likely to attract bets from insiders and, if the defensive actions of bookmakers are the key source of the bias, that greater bias should be observed in those races. In addition, if the actions of bettors and the pricing policies of bookmakers contribute to the bias, one might expect FLB in both the pari-mutuel and the bookmaker markets, but greater bias in the bookmaker market.

The paper is organized as follows. We review the FLB and complexity literatures and use these to develop two propositions relating to the origins of the FLB. We then outline the unique features of the data and the conditional logit model which enable us to assess the degree of FLB across races of varying complexity and attractiveness to insiders. Subsequently, we present and discuss the results which appear to confirm that the FLB is caused by the defensive actions of bookmakers rather than by bettors' cognitive errors. Finally, in the conclusion, we discuss to what extent the results can be generalized.

\section{THE FAVORITE-LONGSHOT BIAS AND COMPLEXITY}

\section{Favorite-longshot bias}

A number of factors have been suggested as the causes of the FLB and it is fair to assume that a variety of elements contribute to the bias. Some researchers have attributed the bias to technical or market-based issues relating to the betting markets themselves, such as, transactions/information costs (e.g., Terrell \& Farmer, 1996; Vaughan Williams \& Paton, 1998), and breakage, whereby, in pari-mutuel markets, odds are rounded down by the pari-mutuel operator to the nearest 0.1 (e.g., Walls \& Busche, 2003). Other researchers have attributed the bias to factors that relate to the preferences and the psychological needs of the bettors such as the desire for excitement (e.g., Bruce \& Johnson, 1992), risk loving preferences (e.g., Hamid, Prakash, \& Smyser, 1996; Quandt, 1986; Weitzman, 1965), additional utility associated with long odds betting (e.g., Snyder, 1978; Thaler \& Ziemba, 1988), and desire for positive skewness (e.g., Walls \& Busche, 2003). 
This paper evaluates two additional explanations for the decision bias, one bettor-based and the other bookmaker-based. These, respectively, attribute much of the bias to bettors' cognitive errors and bookmakers' pricing policy.

The FLB has been linked to a number of cognitive errors on the part of bettors such as overweighting small probabilities and underweighting larger ones (e.g., Kahneman \& Tversky, 1979), inappropriate discounting of losses (e.g., Henery, 1985), use of extraneous information (e.g., Thaler \& Ziemba, 1988), and random misperceptions of objective probabilities (e.g., Chadha \& Quandt, 1996). Indeed, Snowberg and Wolfers (2005), in an extensive analysis of the FLB, suggested that bettors' misperceptions of probabilities are the most likely explanation for the bias. Clearly, if circumstances led to an increase in bettors' errors, then this would, other things being equal, increase the FLB. For example, if the number of random errors made by bettors increased or if bettors resorted to greater use of factors unconnected with a horse's objective probability of success (e.g., basing decisions on the horse's name/number etc.), then bets would be distributed more equally amongst horses than the objective probabilities merit. This would lead to greater under-betting of favorites and over-betting of longshots (Thaler \& Ziemba, 1988).

An alternative view attributes the bias to bookmakers' pricing policy in response to adverse selection. Shin (1991, 1992, 1993) argued that insiders are most likely to bet with bookmakers. This arises because they can secure the odds available at the time bets are struck (which is not possible in pari-mutuel markets), thus avoiding a reduction in odds that could result from the "followship" behavior of those who do not possess privileged information, but who rely on market signals to inform their betting decisions. Shin (1992) argued that bookmakers reduce the odds on longshots because a relatively small bet by an insider on these horses can have a significant effect on the bookmakers' liabilities. In addition, bookmakers may offer favorites at relatively attractive odds because the market for short odds horses is very competitive, and bookmakers are not only concerned about their percentage profit but also their turnover (Tuckwell, 1983). As demonstrated in Table 1, for one particular race, the odds implied probabilities (normalized) for favorites are less than the estimated win probabilities, and those for longshots are considerably more than the estimated win probabilities. However, when the average bookmaker margin of around 20 percent is added back to the normalized probabilities, it is clear that bookmakers still make a profit (on average) on favorites. This is clearly a much smaller percentage profit than they make on longshots, but since the majority of bets will be placed on short odds horses, attracting more bets on favorites can actually increase their overall profit per race. In a few races, bookmakers may even be tempted to offer favorites at odds where their expected return on these horses is slightly negative. They may effectively offer these as "loss leaders" in the expectation that

Table 1. A comparison of odds implied winning probabilities and estimated winning probabilities for two values of our measure of favorite-longshot bias $(\beta)$, for horses in a "typical" 10 horse race $^{1}$

\begin{tabular}{|c|c|c|c|c|c|}
\hline \multirow[b]{2}{*}{ Odds } & \multirow{2}{*}{$\begin{array}{c}\text { Odds implied } \\
\text { probability (normalized) }\end{array}$} & \multicolumn{2}{|l|}{$\beta=1.05$} & \multicolumn{2}{|l|}{$\beta=1.17$} \\
\hline & & Estimated win prob. & Ratio $^{2}$ & Estimated win prob. & Ratio $^{2}$ \\
\hline $7 / 4$ & 0.3193 & 0.3321 & 1.0401 & 0.3628 & 1.1362 \\
\hline $7 / 2$ & 0.1951 & 0.1980 & 1.0149 & 0.2039 & 1.0451 \\
\hline $5 / 1$ & 0.1464 & 0.1464 & 1.0000 & 0.1456 & 0.9945 \\
\hline $7 / 1$ & 0.1098 & 0.1082 & 0.9854 & 0.1040 & 0.9472 \\
\hline $14 / 1$ & 0.0585 & 0.0559 & 0.9556 & 0.0499 & 0.8530 \\
\hline $16 / 1$ & 0.0517 & 0.0491 & 0.9497 & 0.0431 & 0.8337 \\
\hline $25 / 1$ & 0.0338 & 0.0314 & 0.9290 & 0.0262 & 0.7751 \\
\hline $25 / 1$ & 0.0338 & 0.0314 & 0.9290 & 0.0262 & 0.7751 \\
\hline $33 / 1$ & 0.0258 & 0.0237 & 0.9186 & 0.0191 & 0.7403 \\
\hline
\end{tabular}

${ }^{1} \mathrm{An}$ example race run at 2:30 pm on 24 June 2004 in Chester.

${ }^{2}$ Ratio $=$ ratio of estimated winning probability to odds implied probability (normalized). 
it will attract bets on other horses in the race, on which they will make a substantial positive profit. Some knowledgeable, returns-seeking bettors may seek to capitalize on this pricing policy. However, the large profit margin which bookmakers build into odds prevents bettors from developing a consistently profitable strategy (Snowberg and Wolfers, 2005), and this may deter such betting activity. In addition, bookmakers may tolerate some bettors gaining from their pricing strategy if it enables bookmakers to increase turnover and, hence, to increase overall profits.

Shin (1992) also argued that bookmakers believe they face a potentially larger number of insiders in certain types of race. Consequently, in these races they reduce the odds more on longshots and, as a result, the FLB increases. Some support for this view is given by the empirical work of Bruce and Johnson (2000) and Vaughan Williams and Paton (1997).

\section{Complexity}

Complexity, in a betting context, can be defined by the underlying computational demands of the decision task. A mismatch is more likely to occur between the computational demands and the cognitive resources available as complexity increases (e.g., Dror et al., 1999; Eiser \& van der Pligt, 1988; Payne, Bettman, \& Johnson, 1993). The rise in information load induced by complexity may lead to the application of a variety of simplifying decision strategies (e.g., Agnew \& Brown, 1986; Keren and Wagenaar, 1985; Onken, Hastie, \& Revelle, 1985; Sundstroem, 1989). Complexity may arise due to a range of factors such as time pressure, the intensity and complexity of the actual computations, an increase in the heterogeneity of information (e.g., Doerner, 1980; Brehmer, 1992), and working memory requirements. Many of these factors are related to the volume of decision-related information, which in turn increases with the number of alternatives ("alternative-based complexity": e.g., Payne et al., 1993; Timmermans, 1993).

Complexity is also dependent on the ease with which alternatives can be discriminated on the basis of their attributes (e.g., Hogarth, 1975; Rumelhart \& Greeno, 1971; Tversky, 1972). A variety of factors has been shown to be related to such "attribute-based complexity", including the presence of complicated relationships between attributes (Klein \& Yadav, 1989; Sung \& Johnson, 2007), relative similarity (e.g., Biggs, Bedard, Gaber, \& Linsmeirer, 1985; Bockenholt, Albert, Aschenbrenner, \& Schmalhofer, 1991), and ambiguity in the value of attributes (e.g., Ritov \& Baron, 1990).

In general, previous studies have suggested that as both alternative- and attribute-based complexity increase individuals tend to use simpler, non-compensatory, often heuristic-based choice strategies (e.g., Payne et al., 1993). It is not surprising, therefore, that increasing complexity has been shown to be associated with an increase in effort, confusion and choice time (Klein \& Yadav, 1989), a rise in the number of errors (Reason, 1990), and a consequent reduction in performance (Jacoby, Speller, \& Berning, 1975; Jacoby, Speller, \& Kohn, 1974; Malhotra, 1982).

In the next section, the FLB and complexity literature are combined to develop two testable propositions associated with the source of the bias.

\section{PROPOSITIONS, DATA, AND METHODS}

\section{Propositions \\ Cognitive error proposition}

The first proposition, which has been suggested by a number of authors (e.g., Snowberg and Wolfers, 2005), is that errors and misperceptions on the part of bettors cause the FLB. To test this proposition we make use of the positive correlation, established in the literature (as discussed above), between complexity and decision errors. In particular, we identify those races associated with greater alternative- and/or attribute-based complexity and establish whether the FLB increases with the level of complexity. 
Racing experts argue that, ceteris paribus, the larger the number of horses in a race the more complex is the decision task (see Cotton, 1990). Consequently, we measure the degree of alternative-based complexity in a race by the number of runners (see Johnson \& Bruce, 1998).

In testing the cognitive error proposition, we also make use of the suggestion in a number of studies (e.g., Bruce \& Johnson, 1996; Johnson \& Bruce, 1997, 1998) that the degree of attribute-based complexity is greater in "handicap" races. In handicaps, horses are assigned weights to carry based of their previous performances; those that have performed well receiving more weight. The aim is to create competitive races that should, in theory, finish in a dead-heat. Consequently, the weight variable complicates the process of discriminating horses on the basis of their attributes. Weights designed to level ability are not generally applied to non-handicap races and most racing professionals suggest that the process of selecting winners of non-handicaps is less complicated (see, for example, Duncan, 1989; Hall, 1994). This view is supported by the results of races run during 2004: favorites won 39 percent of non-handicaps but only 29 percent of handicaps, and first and second favorites won 63 percent of non-handicaps but only 47 percent of handicaps. In addition, Crafts (1985) demonstrated that odds movements in non-handicaps (cf. handicaps) are a better guide to the likely winner.

It might be argued that differential weights, allocated by the official handicapper to horses of varying ability, have the effect of nullifying differences in ability demonstrated by horses' past performances; thus enabling the bettor to reduce the set of attributes that they need to consider. However, this ignores the complications that arise when assessing the prospects of horses carrying different weights. In particular, experts advise (e.g., Mordin, 1992) that account must be taken of subtle interactions between weight and a range of variables because weight acts as a greater anchor under certain conditions (e.g., in faster run races on tracks with easy turns, in soft/waterlogged conditions, over longer distances). Other experts advise that "weight has only an incidental effect on the outcome of most horse races" (Mordin, 1992, p. 124). Equally, it is well-known that trainers exploit the handicapping system by running horses over inappropriate distances or in unsuitable ground conditions, thus disguising their true ability, leading to their horses being allocated less weight than they should in subsequent races. The bettor must assess all these subtleties in handicap races and they must make a judgment of how well the official handicapper's weight allocation has accounted for the horses' ability, revealed in previous performances.

In summary, handicaps fit closely with the definitions afforded relatively high attribute-based complexity: weights assigned to horses are designed to make the race more competitive (Hogarth, 1975), complicated relationships exist between attributes that confound analysis of the set of attributes resulting from subtle interactions between the effect of weight and other factors (Klein \& Yadav, 1989), and there is ambiguity in the value of attributes, to the extent that it is difficult to discern to what degree weight allocations can be relied upon. Each of these factors can hinder discrimination between horses based on their past performances because fewer alternatives can be easily eliminated (e.g., Ritov and Baron, 1990).

There is a direct relationship between odds in the pari-mutuel market and the judgments and behavior of bettors: odds for horse $i$ in race $j$ are directly related to the proportion of money bet on horse $i$ in race $j$, and bettors will continue to place money on horse $i$ until the odds are in line with their subjective probability judgments (Figlewski, 1979). Consequently, the cognitive error proposition would be supported if the FLB in the pari-mutuel market were higher in races associated with greater degrees of alternative- and attributebased complexity (i.e., in large runner races and in handicaps).

Bookmakers adjust odds to take account of both the relative amount of money wagered on each horse and their own subjective judgments. Consequently, in bookmaker markets, any relationship observed between races involving different levels of complexity and the FLB may be influenced by the behavior of both bettors and bookmakers. Despite this, one would expect bettors in the bookmaker and pari-mutuel markets to be subject to similar cognitive errors and, therefore, the cognitive error proposition would be supported if a positive relationship were observed in the bookmaker market between FLB and race complexity. 


\section{Pricing proposition}

Proposition two, based on the views of Shin (1992), is that the FLB is caused by bookmakers setting odds in a manner to protect themselves from the bets of those with access to privileged information (insiders). To test this "pricing proposition," we first identify those races most likely to attract the bets of insiders and test whether FLB in bookmaker markets is greater for these races.

Previous research suggests two means of categorizing races on the basis of their attractiveness to insiders: First, Shin (1992) suggests that bookmakers are particularly wary of races involving a large number of runners since more horses equates to a greater potential number of insiders (e.g., trainers, owners, and jockeys). Secondly, it has been suggested that non-handicap races attract more bets from insiders than handicap races (Bruce \& Johnson, 2005). Handicap races only involve horses that have previously won or that have run at least three times, and, consequently, their previous performance is a matter of public record. Nonhandicap races, on the other hand, often feature horses that have either never run or have little public visibility. In addition, the weights carried by horses in non-handicap races are often at the discretion of the trainer/owner. Consequently, those closely connected with the horses and their performances away from public scrutiny (e.g., during training) can be regarded as having something of an advantage over the rest of the betting public in these races. There are some exceptions to this general rule. For example, some non-handicap races (events, such as, the Derby) feature horses whose previous performances are well exposed to public scrutiny. In addition, as indicated above, there is a view that some trainers deliberately engage in tactics in handicap races to ensure that their horses are allocated lower than their fair weight in subsequent races; providing those with privileged knowledge a betting opportunity. Despite these exceptions, non-handicap races are generally regarded as the medium through which insiders are most likely to be able to exploit their relative advantage. Consequently, one might expect bookmakers to price more defensively in non-handicap races, particularly those with a large number of horses.

The foregoing discussion suggests some approaches for testing the "pricing proposition." In particular, this proposition would be supported if the FLB in bookmaker markets was greater in races with a larger number of runners and in non-handicaps. However, if a positive correlation is observed between the degree of FLB and the number of runners in bookmaker markets, this may result from an increase in bettors' cognitive errors (as alternative-based complexity increases) and/or as a result of the defensive pricing of bookmakers. In this case, the pricing proposition would be supported (over the cognitive error proposition) if an increase in FLB in the bookmaker market as field size increases were not accompanied by an increase in the bias in parimutuel markets.

\section{Data}

The propositions are tested using data collected from both the bookmaker and pari-mutuel betting markets for horseraces run in the UK during 2004. As indicated above, previous research suggests that the FLB has been persistent across time and this is confirmed by comparing the results (presented below) obtained from analyzing 1996 data from the UK bookmaker and pari-mutuel betting markets, employed originally in Bruce and Johnson (2000), with the results of the current study. Consequently, the 2004 data employed in this study is regarded as a random sample drawn from all races run in the UK over recent years.

For each horse the closing pari-mutuel and bookmaker markets prices (odds) and their finishing positions are recorded. The bookmaker odds for each horse are readily available but comparison of prices in these two markets has been limited in the past because only the pari-mutuel odds of winning or placed horses are made public. However, cooperation of the pari-mutuel operator in the UK (the Tote) afforded us the opportunity to access and employ the full profile of odds for each horse.

The method (the conditional logit model) we employed to investigate the degree of the FLB requires that only one winner is identified in a race, and, consequently, races with more than one winner (i.e., dead-heats) were removed from the dataset. In addition, races with incomplete data (e.g., where horses are withdrawn too 
late for the market prices to adjust appropriately) were also removed. The final dataset employed consisted of 92430 horses in 8545 races across 60 different racetracks. The number of horses in each race varied from 2 to 39 , with a mode of 12 and a mean of 10.28 .

\section{Method}

In searching for the origins of the FLB, Bruce and Johnson (2000) examined differences in the incidence of the bias between bookmaker and pari-mutuel markets by assessing discrepancies between the actual winning probabilities of horses with various odds and the probabilities implied by those odds. This approach may mask differences in the bias in odds at a race level between the two markets. In addition, it does not offer the opportunity for testing whether cognitive errors on the part of bettors are responsible for the bias. To overcome these drawbacks, whilst accounting for within-race competition, a conditional logit modeling approach was employed to assess the degree of FLB in both the bookmaker and pari-mutuel markets for different types of race, defined by their level of complexity. We illustrate this approach in relation to the parimutuel market: First, a "winningness" index $W_{i j}$ for horse $i$ in race $j$ is developed, such that

$$
W_{i j}=\beta \ln \left(p_{i j}^{p}\right)+\varepsilon_{i j}
$$

where $p_{i j}^{p}$ is the normalized final pari-mutuel odds on horse $i$ in race $j$, such that $\sum_{i=1}^{n_{j}} p_{i j}^{p}=1\left(n_{j}\right.$ is the number of horses in race $j), \beta$ is a coefficient that measures the importance of $\ln \left(p_{i j}^{p}\right)$ in determining the likelihood of horse $i$ winning race $j$, and $\varepsilon_{i j}$ is an independent error term. $W_{i j}$ is defined such that the horse that is observed to win a particular race has the largest winningness index of all horses in that race. Consequently, the estimated probability of horse $J$ winning race $j\left(p_{J j}\right)$ is given as follows:

$$
p_{J j}=\operatorname{Prob}\left(W_{J j}>W_{i j}, i=1,2, \ldots n_{j}, i \neq J\right)
$$

Consequently,

$$
p_{J j}=\operatorname{Prob}\left(\beta \ln \left(p_{J j}^{p}\right)+\varepsilon_{J j}>\beta \ln \left(p_{i j}^{p}\right)+\varepsilon_{i j}, i=1,2 \ldots n_{j}, i \neq J\right)
$$

The $W_{i j}$ cannot be observed directly. However, whether horse $i$ wins race $j$ can be observed and a win/lose variable $w_{i j}$ (dichotomy variable) is defined such that

$$
\begin{array}{ll}
w_{i j}=1 & \text { if } W_{i j}=\operatorname{Max}\left(W_{1 j}, W_{2 j}, \ldots, W_{n_{j j}}\right) \\
w_{i j}=0 & \text { otherwise }
\end{array}
$$

Consequently, the estimated probability of horse $J$ winning race $j$ given in Equation (3) can be represented as follows:

$$
p_{J j}=\operatorname{Prob}\left(w_{J j}=1 \mid \ln \left(p_{i j}^{p}\right), i=1,2 \ldots, n_{j}\right)
$$

McFadden (1974) demonstrates that if it is assumed that the error terms $\varepsilon_{i j}$ in Equation (3) are independent and distributed according to the double exponential distribution, this produces the conditional logit (CL) function, where the probability of horse $i$ winning race $j$ is given as follows (Johnson \& Bruce, 2001, p. 285):

$$
p_{i j}=\frac{\exp \left[\beta \ln \left(p_{i j}^{p}\right)\right]}{\sum_{i=1}^{n_{j}} \exp \left[\beta \ln \left(p_{i j}^{p}\right)\right]}=\frac{\left(p_{i j}^{p}\right)^{\beta}}{\sum_{i=1}^{n_{j}}\left(p_{i j}^{p}\right)^{\beta}}
$$


The parameter $\beta$ was estimated for a particular group of races by maximizing the joint probability of observing the results of all races in that group. If the estimated value of $\beta$ is equal to one then this implies that the probabilities derived from the odds are exactly in line with the objective probabilities. Similarly, if the estimated value of $\beta$ is greater than one then this indicates the presence of the FLB and larger values of $\beta$ indicate a greater degree of bias (Bacon-Shone, Lo, \& Busche, 1992).

In the manner indicated above, values of $\beta$ were determined for races with different numbers of horses (i.e., varying levels of alternative-based complexity) in both handicap and non-handicap races (i.e., relatively high and low attribute-based complexity, respectively) using both pari-mutuel and bookmaker final odds. A comparison of the resulting values of $\beta$ was used to assess to what extent the degree of FLB varies across races of different levels of complexity in these two parallel markets. For a given $\beta$ value for a particular group of races, it is difficult to provide a simple means of translating this into the degree to which the estimated winning probability of a horse differs from its odds implied probability. This arises because the difference in probability will depend on the distribution of odds available on all horses in a particular race. To provide some guide to this relationship, a comparison of estimated winning probabilities and odds implied probabilities is given in Table 1 (for values of $\beta$, identified later as applying to the bookmaker and pari-mutuel markets) for one "typical" race, involving the mean number of runners in the dataset employed in this study.

The value of the proposed technique for assessing the true degree of FLB in a market is illustrated by a reworking of the 1996 UK horserace data (19396 horses, in 2109 races) employed in Bruce and Johnson (2000). They explored deviations of actual winning probability from those implied in the odds without directly accounting for within-race competition and, as a result, they detected no significant bias in the parimutuel market. However, using the methodology adopted here on the 1996 data we identify a significant FLB in both the bookmaker and pari-mutuel markets, but significantly larger bias in the former market $(\beta$ $($ bookmaker $)=1.26, t=6.84, p<.01$ and $\beta$ (pari-mutuel) $=1.09, t=2.83, p<.01$; difference: $t=3.24$, $p<.01$ ). This is a similar result to that reported for the 2004 data employed in the current study (see Results Section below).

The methodology employed in Bruce and Johnson (2000) was also used to analyze the 2004 data and yielded remarkably similar results to those reported in the earlier paper (see Table 2), in terms of the predicted winning probabilities for horses in various odds ranges.

Table 2. A comparison of predicted winning probabilities (arising from pari-mutuel and bookmaker odds) between those produced in Bruce and Johnson (2000) and those produced employing the Bruce and Johnson's (2000) methodology on 2004 data

\begin{tabular}{|c|c|c|c|c|c|}
\hline \multirow[b]{3}{*}{ Odds } & \multirow{3}{*}{$\begin{array}{l}\text { Normalized odds } \\
\text { implied prob. }\end{array}$} & \multicolumn{4}{|c|}{ Predicted probability of winning } \\
\hline & & \multicolumn{2}{|c|}{ Bookmaker odds } & \multicolumn{2}{|c|}{ Pari-mutuel odds } \\
\hline & & $\mathrm{B} \& \mathrm{~J}$ data $^{1}$ & 2004 data $^{2}$ & $\mathrm{~B} \& \mathrm{~J}$ data $^{3}$ & 2004 data $^{4}$ \\
\hline $1 / 1$ & 0.500 & 0.500 & 0.480 & 0.430 & 0.437 \\
\hline $8 / 1$ & 0.111 & 0.089 & 0.093 & 0.090 & 0.094 \\
\hline $50 / 1$ & 0.020 & 0.008 & 0.010 & 0.015 & 0.016 \\
\hline $100 / 1$ & 0.010 & 0.003 & 0.004 & 0.008 & 0.008 \\
\hline
\end{tabular}

${ }^{1}$ Results obtained in Bruce and Johnson (2000), employing: $\ln ($ predicted prob. $)=-0.681-0.612 \ln \left(O^{b}\right)-0.117\left[\ln \left(O^{b}\right)\right]^{2}$ where $O^{b}$ is bookmaker odds. $\left[R^{2}=0.999\right.$, degree of freedom $\left.=19393, F=1.8 \mathrm{E}+7(p<0.0001)\right]$.

${ }^{2}$ Results obtained using the Bruce and Johnson's (2000) methodology on 2004 data, employing: $\ln$ ( predicted prob.) $=-0.736-0.498$ $\ln \left(O^{b}\right)-0.155\left[\ln \left(O^{b}\right)\right]^{2}+0.007\left[\ln \left(O^{b}\right)\right]^{3}\left[R^{2}=0.999\right.$, degree of freedom $\left.=92426, F=2.3 \mathrm{E}+7(p<0.0001)\right]$.

${ }^{3}$ Results obtained in Bruce and Johnson (2000), employing: $\ln ($ predicted prob. $)=-0.821-0.602 \ln \left(O^{t}\right)-0.093\left[\ln \left(O^{t}\right)\right]^{2}+0.007$ $\left[\ln \left(O^{t}\right)\right]^{3}$, where $O^{t}$ is pari-mutuel odds. $\left[R^{2}=1.00\right.$, degree of freedom $\left.=19392, F=3.4 \mathrm{E}+7(p<0.0001)\right]$.

${ }^{4}$ Results obtained using the Bruce and Johnson's (2000) methodology on 2004 data, employing: $\ln ($ predicted prob.) $=-0.827-0.549$ $\ln \left(O^{t}\right)-0.110\left[\ln \left(O^{t}\right)\right]^{2}+0.009\left[\ln \left(O^{t}\right)\right]^{3}\left[R^{2}=0.999\right.$, degree of freedom $\left.=92426, F=3.5 \mathrm{E}+7(p<0.0001)\right]$. 
Taken together, comparisons of the results of the application of the methodology suggested here with that employed in Bruce and Johnson (2000) confirm our decision to account for within-race competition using a CL model in this study; it is through this medium that the true incidence of the bias is unmasked.

\section{RESULTS}

A CL model for the pari-mutuel market was estimated for all races run during 2004. The results, presented in Table 3, demonstrate that this market displays a significant FLB $(\beta$ (pari-mutuel) $=1.0502, t=3.45, p<.01)$.

To formally test the cognitive error proposition, an analysis is conducted, in the pari-mutuel market, of the degree to which the FLB varies across races with different numbers of runners and between handicaps and non-handicaps. These results are presented in Tables 3 and 4. A scatter plot of the coefficients for the CL models developed for each set of races, defined by the number of runners (see Figure 1), suggests that the degree of FLB in the pari-mutuel market does not increase as the number of horses increases. Curve fit facilities within SPSSX were employed to plot the best fit line associating the number of runners per race and the degree of FLB. The regression results shown in Figure 1 indicate that there is no relationship between these variables in the pari-mutuel market (e.g., $R^{2}=0.04$; $t$ value of field size parameter $=-0.75$ ). In addition, for the pari-mutuel market, no FLB is detected in the high attribute-based complexity races (handicaps: $\beta=0.9802, t=-0.85$; see Table 4), but the bias does exist in low attribute complexity races (non-handicap races: $\beta=1.0936, t=4.98$ ). Moreover, there is no increase in the bias in those races associated with the most extreme complexity: handicap races with large numbers of runners (i.e., high attribute- and alternative-based complexity).

Table 3. Coefficients of conditional logit models for races with different numbers of runners in the UK pari-mutuel and bookmaker markets

\begin{tabular}{lccccccc}
\hline $\begin{array}{l}\text { No. of } \\
\text { horses } \\
\text { per race }\end{array}$ & $\begin{array}{c}\text { No. of } \\
\text { races }\end{array}$ & $\begin{array}{c}\text { Pari-mutuel } \\
\text { market } \\
\text { coefficient }(\beta)\end{array}$ & $t$-value & $\begin{array}{c}\text { SD of } \\
\text { pari-mutuel } \\
\text { odds }\end{array}$ & $\begin{array}{c}\text { Range of } \\
\text { pari-mutuel } \\
\text { odds }\end{array}$ & $\begin{array}{c}\text { Bookmaker } \\
\text { Market } \\
\text { coefficient }(\beta)\end{array}$ \\
\hline $2-4$ & 244 & 0.9606 & -0.35 & 4.37 & 9.39 & 0.9518 & -0.44 \\
5 & 369 & 1.0914 & 1.08 & 8.72 & 20.76 & 1.1178 & 1.34 \\
6 & 575 & 1.1565 & $2.37^{*}$ & 11.64 & 29.57 & 1.2062 & $2.97^{* *}$ \\
7 & 670 & 1.0862 & 1.48 & 14.04 & 37.70 & 1.1756 & $2.78^{* *}$ \\
8 & 804 & 1.0429 & 0.87 & 16.12 & 45.52 & 1.0892 & 1.74 \\
9 & 789 & 1.0912 & 1.84 & 19.23 & 56.60 & 1.1764 & $3.29^{* *}$ \\
10 & 830 & 1.0255 & 0.56 & 22.26 & 67.33 & 1.1102 & $2.24^{*}$ \\
11 & 757 & 1.0442 & 0.93 & 25.85 & 80.49 & 1.2032 & $3.78^{* *}$ \\
12 & 801 & 0.9868 & -0.29 & 26.63 & 84.73 & 1.1225 & $2.41^{*}$ \\
13 & 692 & 1.0796 & 1.59 & 28.51 & 93.48 & 1.2101 & $3.78^{* *}$ \\
14 & 604 & 1.0332 & 0.66 & 32.33 & 107.21 & 1.1700 & $2.99^{* *}$ \\
15 & 389 & 1.0403 & 0.65 & 34.71 & 117.99 & 1.2087 & $2.95^{* *}$ \\
16 & 314 & 1.0997 & 1.42 & 37.05 & 128.10 & 1.2620 & $3.29^{* *}$ \\
17 & 194 & 1.0424 & 0.47 & 38.48 & 136.85 & 1.2610 & $2.43^{*}$ \\
$18-39$ & 513 & 1.0013 & 0.02 & 44.73 & 165.40 & 1.2213 & $3.62^{* *}$ \\
Total & 8,545 & 1.0502 & $3.45^{* *}$ & 23.72 & 75.50 & 1.1666 & $10.35^{* *}$ \\
\hline
\end{tabular}

*Significant at 0.05 .

${ }^{* *}$ Significant at 0.01 .

${ }^{1}$ Mean SD of odds in races with a given number of runners. 


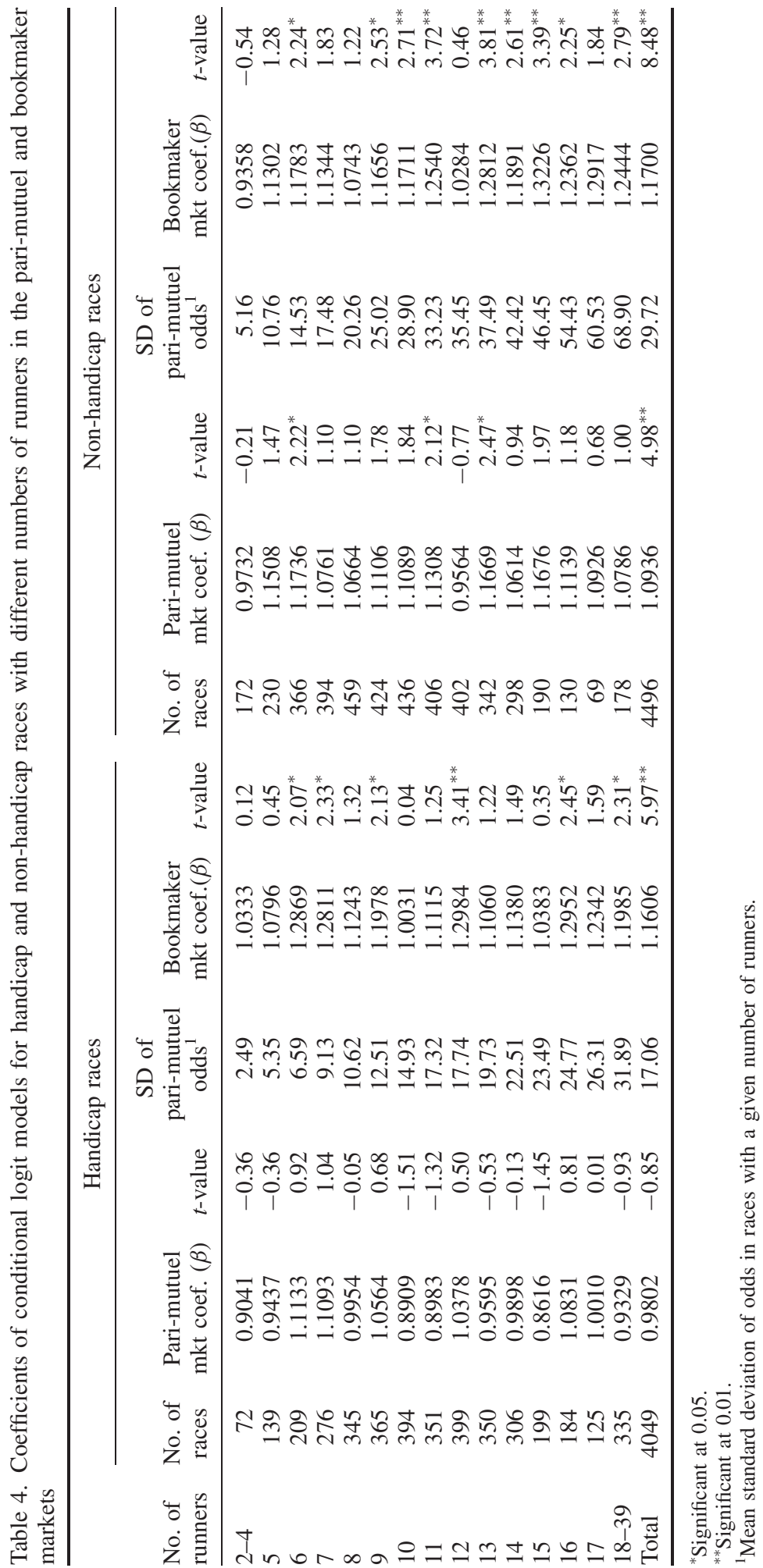




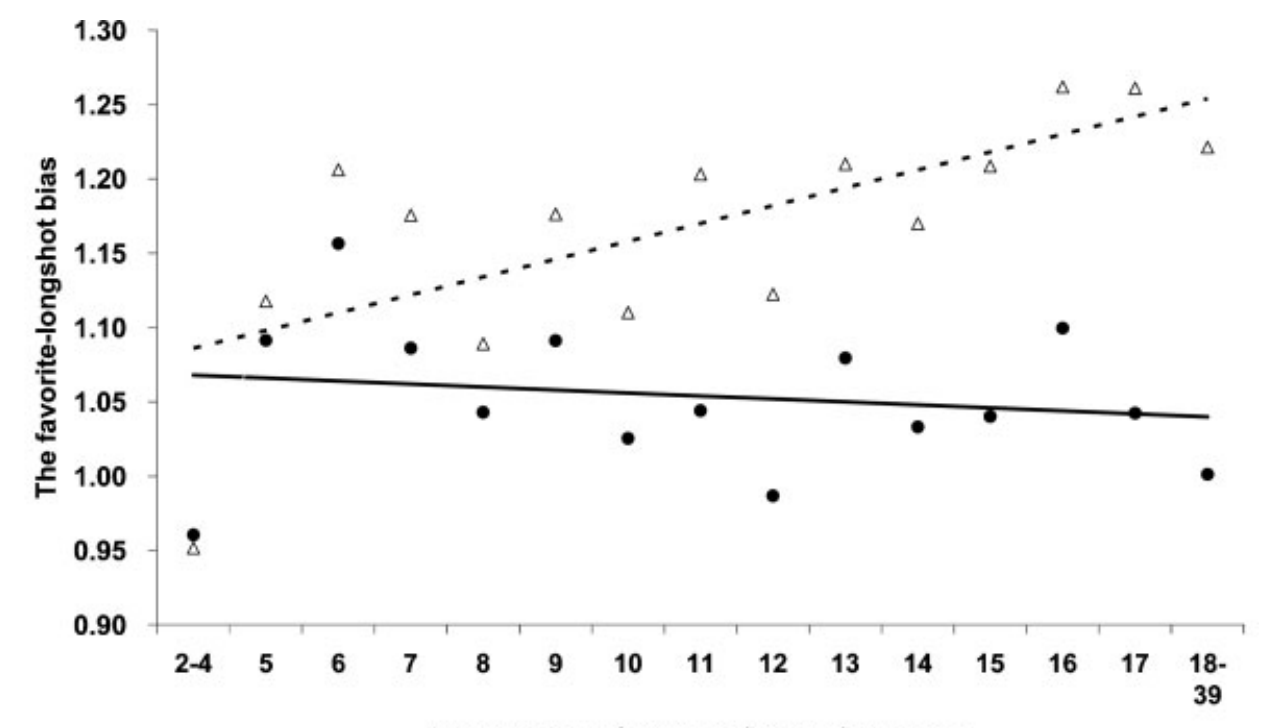

The number of choices (horses) in a race

- Observations of the degree of FLB in the pari-mutuel market

$\Delta \quad$ Observations of the degree of FLB in the bookmaker market

- Best fit regression line for FLB in the pari-mutuel market

... Best fit regression line for FLB in the bookmaker market

Curve fitting results for the relationship between the numbers of runners and the degree of favorite-longshot bias in the pari-mutuel and bookmaker markets

\begin{tabular}{|c|c|c|c|c|c|c|c|}
\hline & & \multicolumn{2}{|c|}{$\begin{array}{l}\text { Unstandardized } \\
\text { coefficients }\end{array}$} & \multirow{2}{*}{$\begin{array}{c}\text { R- } \\
\text { Square }\end{array}$} & \multirow{2}{*}{$\mathrm{t}$} & \multirow{2}{*}{ Sig. } & \multirow{2}{*}{$\mathrm{F}$} \\
\hline & & B & $\begin{array}{l}\text { Std. } \\
\text { Error }\end{array}$ & & & & \\
\hline \multirow[t]{2}{*}{$\begin{array}{l}\text { Pari-mutuel } \\
\text { market }\end{array}$} & $\begin{array}{l}\text { No. of } \\
\text { runners }\end{array}$ & -0.002 & 0.003 & 0.04 & -0.75 & 0.468 & 0.56 \\
\hline & Constant & 1.076 & 0.035 & & 31.16 & 0.000 & \\
\hline \multirow[t]{2}{*}{$\begin{array}{l}\text { Bookmaker } \\
\text { market }\end{array}$} & $\begin{array}{l}\text { No. of } \\
\text { runners }\end{array}$ & 0.012 & 0.003 & 0.47 & 3.42 & 0.005 & 11.68 \\
\hline & Constant & 1.038 & 0.041 & & 25.59 & 0.000 & \\
\hline
\end{tabular}

Figure 1. The degree of favorite-longshot bias in the pari-mutuel and bookmaker markets for races with different numbers of runners

To test whether the differences in the FLB observed in handicap and non-handicap races in the pari-mutuel market center on the degree of competition between runners (rather than from differences in the races' complexity), we explored the relationship between the spread of odds in the pari-mutuel market and the degree of FLB. Clearly, races with a greater spread of odds might be regarded as less competitive, as the odds suggest that there are clear distinctions between the abilities of the runners. The mean spread of odds (measured by standard deviation and the odds range in a race) in races with different numbers of runners for 
the pari-mutuel market as a whole and for handicaps and non-handicaps, separately, are presented in Tables 3 and 4. It is clear from casual observation that there is no relationship in any of these cases between the mean of the spread of odds and the degree of FLB. Regressions of the mean SD of odds in the groups of races (defined by number of runners) against the degree of $\operatorname{FLB}(\beta)$ confirm this observation. For example, a best fit line for the market as a whole suggests that mean $\mathrm{SD}=67.24-40.80 \beta$, but the $R^{2}$ is only 0.029 and the model is not significant $(F=0.392, p>.54)$.

In testing the pricing proposition, we first developed a CL model for the bookmaker market for all races run in 2004 and found that this market displayed a significantly greater FLB than the parallel pari-mutuel market (see Table 3: $\beta$ (bookmaker) $=1.1666, t=10.35, p<.01$; difference: $t=5.37, p<.01$ ). In addition, a significant FLB was detected in the bookmaker market in virtually all categories of races based on the number of runners, whereas there is only one such number of runners category displaying the bias in the pari-mutuel market (see Table 3).

Second, a scatter plot of the degree of FLB against number of runners per race in the bookmaker market suggests a significant positive relationship (see Figure 1); regression analysis performed by curve fit facilities within SPSSX confirmed this view $\left(R^{2}=0.47, t\right.$ value of field size parameter $\left.=3.42\right)$. As indicated above, there is no equivalent increase in the degree of bias as the number of runners per race increases in the parimutuel market.

Third, we compared the degree of FLB in the bookmaker market in handicaps and non-handicaps and the results are given in Table 4. Overall, the degree of bias is similar in the two race types (handicaps: $\beta=1.1606$, $t=5.97$; non-handicaps: $\beta=1.1700, t=8.48$; difference: $t=0.30, p>.05$ ). However, when races are broken down by the number of runners, a significant bias is observed in 50 per cent more of the number of runner categories in non-handicaps than in handicaps (i.e., nine vs. six). Equally, a scatter plot of the degree of bias against number of runners per race and related regression analysis for the bookmaker market (shown in Figure 2) indicates that there is a clear increase in the bias in non-handicaps as the number of runners increases but not in handicaps (non-handicaps: $R^{2}=0.47, t$ value of field size parameter $=3.38$; handicaps: $R^{2}=0.04, t$ value of field size parameter $=0.76$ ).

\section{DISCUSSION}

\section{Bettor-based explanations for the favorite-longshot bias \\ The role of complexity}

The results demonstrate that a significant FLB exists in the pari-mutuel market, where odds are determined solely by bettors' decisions. This suggests that the behavior of bettors, at least to some extent, causes the bias.

The cognitive error proposition is based on the conclusion to emerge from previous research that an increase in complexity often results in simpler, non-compensatory strategies being employed (e.g., Onken et al., 1985; Payne et al., 1993). This leads to greater cognitive errors (Reason, 1990), which in turn have a detrimental effect on decision-making (e.g., Malhotra, 1982; Wright, 1975). In a betting market context, this suggests that bettors may turn to simpler criteria for selecting horses (e.g., in extremis, basing their selection on the horse's name) and may make more random errors in races involving greater complexity. This in turn would lead to a greater FLB as bets would be distributed more equally across the horses in a race than their true probabilities of winning required. Consequently, if the FLB were caused by cognitive errors on the part of bettors, then there should be an increase in errors (and hence greater FLB) in races associated with greater complexity (i.e., those with more runners and handicaps). In addition, the effect should be most noticeable in races associated with extreme complexity (handicap races with many runners). Malhotra (1982), for example, noted particularly dysfunctional effects of complexity on decision-making when the number of alternatives exceeds 10 and Johnson and Bruce (1998) identified the multiplicative effects of alternative- and attribute-based complexity. However, the results displayed in Figure 1 and Table 4 show that 


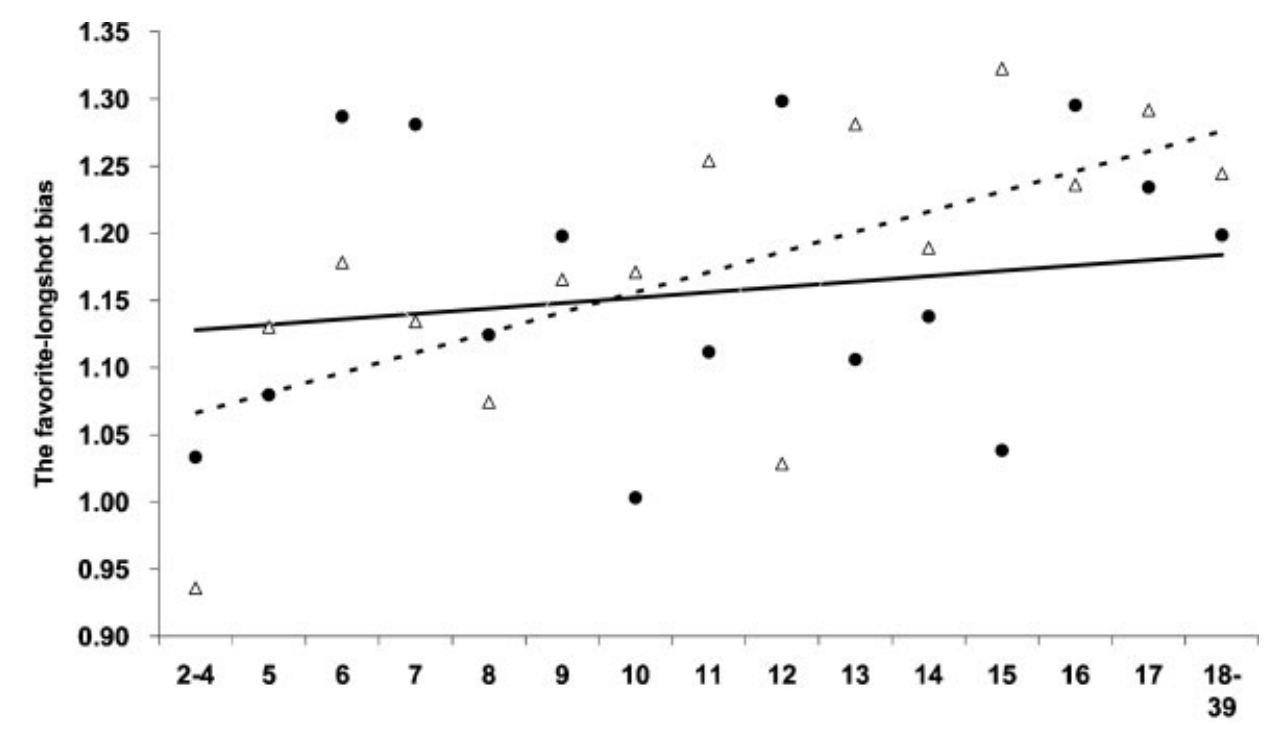

The number of choices (horses) in a race

- Observations of the degree of FLB in handicap races

$\Delta \quad$ Observations of the degree of FLB in non-handicap races

- Best fit regression line for FLB in handicap races

... Best fit regression line for FLB in non-handicap races

Curve fitting results for handicap and non-handicap races in the bookmaker market

\begin{tabular}{|c|c|c|c|c|c|c|c|}
\hline & & \multicolumn{2}{|c|}{$\begin{array}{l}\text { Unstandardized } \\
\text { coefficients }\end{array}$} & \multirow{2}{*}{$\begin{array}{c}\text { R- } \\
\text { Square }\end{array}$} & \multirow{2}{*}{$\mathrm{t}$} & \multirow{2}{*}{ Sig. } & \multirow{2}{*}{$\mathrm{F}$} \\
\hline & & B & $\begin{array}{l}\text { Std. Er- } \\
\text { ror }\end{array}$ & & & & \\
\hline \multirow[t]{2}{*}{ Handicaps } & $\begin{array}{l}\text { No. of } \\
\text { horses }\end{array}$ & 0.004 & 0.006 & 0.04 & 0.76 & 0.464 & 0.57 \\
\hline & Constant & 1.112 & 0.071 & & 15.76 & 0.000 & \\
\hline \multirow[t]{2}{*}{$\begin{array}{l}\text { Non- } \\
\text { handicaps }\end{array}$} & $\begin{array}{l}\text { No. of } \\
\text { horses }\end{array}$ & 0.015 & 0.005 & 0.47 & 3.38 & 0.005 & 11.41 \\
\hline & Constant & 1.006 & 0.054 & & 18.58 & 0.000 & \\
\hline
\end{tabular}

Figure 2. The degree of favorite-longshot bias in the bookmaker market for handicap and non-handicap races with different numbers of runners

FLB in the pari-mutuel market does not increase as alternative and/or attribute complexity increase; even in races associated with the most extreme complexity. Odds in pari-mutuel markets are directly determined by the subjective judgments of bettors. Consequently, the results suggest that bettors' cognitive errors may not be the cause of the bias. However, before dismissing a cognitive error explanation for the FLB it is important to explore alternative interpretations of the results and a number of these are now addressed. 


\section{Cognitive error explanations: Simple heuristics}

It is also possible that the FLB observed in the pari-mutuel market as a whole may arise from some bettors selecting winners on the basis of simple heuristics that do not vary with the level of complexity (e.g., always betting on the basis of the horse's name). However, this is not supported by the fact that no FLB exists in high attribute complexity races (handicaps). Equally, the heuristics explanation does not accord with the existence of FLB in low attribute complexity races, where one might expect the task of selecting a potential winner to involve less effort (Klein \& Yadav, 1989), less use of simplifying heuristics (Payne et al., 1993), and less errors (Reason, 1990).

\section{Cognitive error explanations: Differential competition in handicaps/non-handicaps}

The different degrees of FLB observed in handicap and non-handicap races in the pari-mutuel market could center on the degree of competition in these races. Handicaps, via the differential weight allocation, are designed to be more competitive events. As a result, it is expected that the spread of odds between favorites and longshots will be greater in non-handicaps. This would give greater scope for bettors to under/overestimate large/small probabilities in non-handicaps, and it might be argued that this could cause the greater FLB which we observed in non-handicaps (cf. handicaps) in the pari-mutuel market. However, the results displayed in Tables 3 and 4 and the regression results given above suggest that there is no relationship between competitiveness of a race (as measured by the SD of the runners' odds) and the degree of FLB.

\section{Cognitive error explanations: Differential account of past performances}

It is possible that bettors do not take sufficient account of past performances of horses in non-handicap races, and that this results in bets being spread more equally across horses than their objective winning probabilities imply; resulting in the observed FLB in the pari-mutuel market for non-handicap races. In addition, it might be argued that the differential weights applied to horses in handicaps, in an effort to equalize their opportunity of winning, significantly reduces the need for bettors to assess past performances (because the official handicapper would take these into account in assigning weight). Consequently, there is less opportunity for bettors to under-value this cue when assessing winning probabilities, leading to the lack of FLB observed in pari-mutuel odds in handicap races. However, there are reasons to question such a cognitive error based explanation for the bias: First, non-handicap races often involve horses that have had little public exposure, whereas handicaps involve experienced horses (those that have run more than three times or at least have won a race). The scope for under-valuing past performances is, therefore, likely to be limited in non-handicaps (cf. handicaps). Second, as explained fully above, many leading horseracing experts argue that the differential weights applied to horses in handicaps do not diminish the value of past performances in assessing winning probabilities. If anything they argue it complicates such an analysis. Consequently, a cognitive error based explanation for the FLB based on the notion of the differential assessment of past performances in handicap and non-handicap races is not supported by the evidence.

In summary, none of the results support the cognitive error proposition. It is difficult in a naturalistic enquiry to prove that cognitive error is not the source of the FLB, but a compelling case is made against a variety of alternative cognitive accounts of the bias. In particular, the FLB does not increase as complexity increases in markets where odds are determined solely by the actions of bettors. Since cognitive errors have generally been shown to increase with complexity, this result is strongly suggestive of a mechanism other than cognitive error causing the FLB. In addition, the evidence does not support the view that the FLB arises from the application of simple heuristics which do not vary with the level of complexity or as an artifact of greater competition in certain races, which might be thought to increase the scope for under/over estimation 
of large/small probabilities. Finally, we also explain above why it is unlikely that the bias arises from bettors' failure to account for past performances of horses in non-handicap races.

\section{Aggregation and risk preference}

While the evidence presented above does not support a cognitive error account of the bias, the FLB exists in the UK pari-mutuel market examined here and in markets where bets can only be placed with pari-mutuel operators (e.g., USA: Thaler \& Ziemba, 1988). Consequently, some aspect of bettors' behavior must be responsible. It is possible that cognitive errors on the part of individual bettors may result in the FLB, but that a variety of aggregation mechanisms which exist in betting markets mask the effect. In particular, it is possible that different subsets of bettors focusing on different subsets of horses or interactions between bettors, either directly or through their observation of, and reaction to, odds changes, may induce a different relationship between complexity and the "aggregated" cognitive errors. However, this alternative interpretation of our results remains speculative unless further research clarifies the manner in which these aggregating mechanisms operate.

One of the prominent explanations for the FLB in the literature is that the utility curves of bettors display risk preference and that bettors behave rationally in attempting to maximize expected utility (e.g., Quandt, 1986). Consequently, it is their desire for high variance bets on longshots which causes these horses to be over-bet, resulting in the FLB (e.g., Hamid et al., 1996). The results reported above are consistent with this view. We observe the FLB in the pari-mutuel market in low attribute complexity races but not in high attribute complexity races. Previous studies have indicated that risk-taking strategies are modified by the level of complexity (e.g., Capon \& Davis, 1984; Dror et al., 1999; Timmermans, 1993) and Johnson \& Bruce (1998) found that there is some propensity to take greater risk (i.e., bet at higher odds) in low attribute complexity races (i.e., non-handicap races). It is possible that, in line with Wilde's (1988) risk homeostasis, bettors, believing that they face a more certain (less challenging) environment in non-handicap races, bet on longer odds horses because they feel free to take more risk in this "low risk" environment. However, no relationship was found between the degree of FLB in the pari-mutuel market and the number of runners (i.e., between FLB and alternative-based complexity, see Figure 1). This suggests that for the risk preference explanation for the FLB to hold, a different relationship must exist between risk-taking and the degree of attribute or alternative complexity. This is an area which requires further research.

\section{Bookmaker-based explanations for the favorite-longshot bias}

Bookmakers' rational pricing policy

Bettors are likely to display similar patterns of behavior in the bookmaker and the pari-mutuel markets. Consequently, the results displayed in Table 3, which show that the FLB is significantly greater in the bookmaker (cf. pari-mutuel) market, offer support for the bias, at least in part, being caused by the deliberate (rational) pricing policy of bookmakers. Direct support for this pricing proposition is provided by the scatter plot in Figure 1. This suggests that in bookmaker markets the FLB increases as the number of runners in a race increases. This is probably not due to an increase in cognitive errors on the part of bettors since the FLB in pari-mutuel markets does not increase as field size increases (i.e., as alternative-based complexity increases) and it is unlikely that those who bet with bookmakers will be more prone to cognitive errors than those who bet in the pari-mutuel market. In fact, as indicated above, it is expected that those with access to privileged information and who use this information in a more informed manner are more likely to bet with bookmakers than with the pari-mutuel operator, suggesting, if anything, less likelihood of cognitive errors by bettors in the bookmaker market. These results, therefore, support the pricing proposition. This proposition is also supported by Shin $(1991,1992,1993)$ who pointed to the link between the number of runners and the number of informed traders in the market: namely, more horses equates to more trainers, owners, and jockeys 
who may possess privileged information about the true winning chance of the horse. Vaughan Williams and Paton (1997, p.157) confirmed this relationship using UK racetrack data, and concluded that "insider trading is a likely explanation of the positive correlation between sum of prices and the number of runners." They went on to argue that this suggests that at least some of the observed FLB can be explained by bookmakers' defensive pricing.

A comparison of the degree of FLB in the bookmaker market in handicap and non-handicap races is also supportive of the view that defensive pricing is the key source of the bias in bookmaker markets (see Table 4). These results suggest that in bookmaker markets more race categories (defined by numbers of runners) exhibit the FLB for non-handicaps than handicaps. In addition, this phenomenon is more pronounced as the number of horses in a race increases.

As indicated above, there is evidence from previous research that bookmakers face more insiders in races with more runners and in non-handicaps. For example, Crafts (1985) demonstrated that odds forecast on the morning of a race (which should account for all publicly available information concerning a horse's prospects) are a poorer guide to winning probability in non-handicaps (cf. handicaps). He showed that large profits could be achieved by betting at the forecast odds of horses in non-handicaps where the odds subsequently fall significantly as a result of market trading. Furthermore, Law and Peel (2002) demonstrated that races involving the most significant differences between forecast morning odds and closing odds and opening odds and closing odds are those associated with greater betting activity by insiders. As indicated above, non-handicaps often involve horses with little public form, thereby offering greater potential for the profitable use of privileged information. These races offer relatively little information to the public regarding horses' abilities and Smith, Paton, and Vaughan Williams (2006) showed that a greater proportion of bets are placed by insiders in such races. In contrast, handicaps involve horses with more exposed form because they must have run in at least three races or have won a race.

In summary, the results indicate that the FLB is greatest in races where bookmakers expect more insiders (Shin, 1991, 1992, 1993; Vaughan Williams \& Paton, 1997). It appears likely, therefore, that bookmakers deliberately create the FLB as a defensive reaction to the presence of informed traders.

\section{Bookmaker-based cognitive error: support theory}

An alternative, bookmaker-based cognitive explanation for the effect observed may be offered by Rottenstreich and Tversky's (1997) version of support theory. This predicts "subadditivity" in judgments of the likelihood of a set of (explicit) events (e.g., horses winning races) because "unpacking" the event into more elements (more horses to consider as possible winners) increases support for each possible event, and, hence, the sum of the combined probabilities. In line with this theory, Ayton (1997) reports an increase in the sum of the odds implied probabilities (non-normalized) derived from bookmaker odds in the UK as the number of horses in a race increase. Ayton (1997, p. 112) suggests that this may be "disproportionately due to short odds (high probability) horses not being sufficiently discounted in larger races [i.e., increased FLB] which might reflect anchoring or conservatism on the part of bookmakers. It may be that bookmakers who are obliged to consider the full set of possible winners are subject to the mechanisms proposed by support theory, leading to a greater amount of non-additivity in odds in larger races. In addition, because individual parimutuel bettors may only consider a small subset of horses in a given race (particularly in races with a large number of runners), the odds developed in pari-mutuel markets are more likely to be additive. This fits with the observation, reported above, of less FLB in the pari-mutuel market and no increase in the bias in parimutuel odds as the number of runners increase.

This cognitive explanation of the FLB is possible, but it is at odds with one of the key findings of this study. In particular, if support theory explains the FLB displayed in bookmaker odds then one would expect that as the number of runners in a race increase (i.e., the number of elements of the "unpacked problem" increase) the FLB would increase. However, the results reported in Table 4 and Figure 2 demonstrate that whereas this 
is the case for bookmaker odds in non-handicap races it is not true for handicap races. This questions the cognitive explanation because there is nothing in support theory to explain why bookmakers should respond differently to an increase in the number of runners for these two race types.

The bookmaker-based cognitive error account might also be questioned on the basis of bookmakers' level of expertise and the environment in which they operate. In particular, it could be argued that bookmakers, who make their living from horseracing, are likely to devote considerably more time and resources to determining the probability of a horse winning a race than the average bettors. In addition, the market is highly competitive, with many other bookmakers setting odds to attract customers. Consequently, they have a strong motivation to set odds that reflect the true chance of each horse; deviations from such behavior are likely to result in significant economic penalties that could affect their livelihood. These arguments alone cannot be used to dismiss the support theory explanation because the literature offers numerous demonstrations of cognitive bias in experts (e.g., Dror \& Charlton, 2006; Dror \& Rosenthal, 2008; Fox, Brett, Rogers, \& Tversky, 1996). However, experts have been shown to possess superior skills and specialized cognitive mechanisms in a number of domains (e.g., Fingerprint experts: Busey \& Vanderkolk, 2005; Airforce pilots: Dror, Kosslyn, \& Waag, 1993). Importantly, Bolger and Wright (1994), in their exploration of 40 studies of expertise, found that only six groups of experts demonstrated good judgment, and racetrack tipsters were amongst these; suggesting that the conditions which facilitate calibration between subjective and objective probabilities may exist in horserace betting markets (e.g., Johnson and Bruce, 2001). In addition, bookmakers have a particular advantage in the racetrack setting as several of them employ mathematical models to set appropriate odds.

In summary, whilst we cannot completely reject the bookmaker-based cognitive account of the FLB in bookmaker markets offered by support theory, the results are more in line with the pricing proposition. Consequently, it appears that bookmakers, in setting odds to protect themselves from the bets of those with access to privileged information, at least in part, cause the FLB.

\section{CONCLUSION}

In this paper we have sought to assess the competing claims of two sources of the FLB, bettor-based cognitive errors and the deliberate, rational pricing policy of bookmakers. This is achieved by examining how alternative- and attribute-complexity differentially affect the bias across two different types of betting markets. We find clear evidence of two important sources of the bias in the UK bookmaker market: the defensive pricing of bookmakers in the face of a perceived adverse selection problem and bettors' riskseeking behavior. We found no support for the commonly held view in the literature that the bias arises from cognitive errors on the part of bettors. The study, therefore, corroborates the earlier theoretical conclusions of Shin (1993) and the empirical work of Vaughan Williams and Paton (1997) and Bruce and Johnson (2000) and helps to resolve the debate concerning the relative influences of bettors and bookmakers on the bias where the bookmaker and pari-mutuel markets coexist.

Clearly, the results may not translate directly to markets such as the USA and Hong Kong where individuals can only bet with the pari-mutuel operator. In particular, it is possible that the opportunities to compare odds and to bet in the parallel bookmaker and pari-mutuel markets in the UK (and Australia) may result in behavior which differs from that in other markets. In fact, the FLB in the USA (the most researched pari-mutuel market) appears to be slightly greater than that reported here for the UK pari-mutuel market (Gramm and Owens, 2006). However, the FLB in these countries is of a similar order of magnitude and there is overwhelming evidence from across the world that the bias in pari-mutuel markets is not sufficiently large to enable profitable trading (Levitt, 2004). Consequently, while further work is needed to confirm that cognitive error is not a key source of the bias in betting markets where bookmakers do not operate, we are optimistic that this result will hold. 


\section{REFERENCES}

Ali, M. M. (1977). Probability and utility estimates for racetrack bettors. Journal of Political Economy, 85, 803-815.

Agnew, N. McK. \& Brown, J. L. (1986). Bounded rationality: Fallible decisions in unbounded decision space. Behavioral Science, 31, 148-161.

Asch, P., Malkiel, B. G., \& Quandt, R. E. (1982). Racetrack betting and informed behavior. Journal of Financial Economics, 10, 187-194.

Ayton, P. (1997). How to be incoherent and seductive: Bookmakers' odds and support theory. Organizational Behavior and Human Decision Processes, 72, 99-115.

Bacon-Shone, J. H., Lo, V. S. Y., \& Busche, K. (1992). Modeling winning probability, Research Report 10, Department of Statistics, University of Hong Kong.

Biggs, S., Bedard, J., Gaber, B., \& Linsmeirer, T. (1985). The effect of task size and similarity on the decision behavior of bank loan officers. Management Science, 31, 970-987.

Bird, R., \& McCrae, M. (1994). The efficiency of the racetrack betting market: Australian evidence. In D. B. Hausch , V. S. Y. Lo , \& W. T. Ziemba (Eds.), Efficiency of racetrack betting markets (pp. 575-581). London: Academic Press.

Bockenholt, U., Albert, D., Aschenbrenner, M., \& Schmalhofer, F. (1991). The effects of attractiveness, dominance, and attribute differences on information acquisition in multi-attribute binary choice. Organizational Behavior and Human Decision Processes, 49, 258-281.

Bolger, F. A., \& Wright, G. (1994). Assessing the quality of expert judgement. Decision Support Systems, 11, 1-24.

Brehmer, B. (1992). Dynamic decision-making: Human control of complex systems. Acta Psychologica, 81, $211-241$.

Bruce, A. C., \& Johnson, J. E. V. (1992). Toward an explanation of betting as a leisure pursuit. Leisure Studies, 11, 201218.

Bruce, A. C., \& Johnson, J. E. V. (1996). Decision making under risk: Effect of complexity on performance. Psychological Reports, 79, 67-76.

Bruce, A. C., \& Johnson, J. E. V. (2000). Investigating the roots of the favorite-longshot bias: An analysis of supply and demand side agents in parallel betting markets. Journal of Behavioral Decision Making, 13, 413-430.

Bruce, A. C., \& Johnson, J. E. V. (2005). Market ecology and decision behavior in state-contingent claims markets. Journal of Economic Behavior and Organization, 56, 199-217.

Busey, T. A., \& Vanderkolk, J. R. (2005). Behavioral and electro-physiological evidence configural processing in fingerprint experts. Vision Research, 45, 431-448.

Capon, N., \& Davis, R. (1984). Cognitive ability measures as predictors of consumer information processing strategies. Journal of Marketing Research, 11, 551-563.

Chadha, S., \& Quandt, R. E. (1996). Betting bias and market equilibrium in racetrack betting. Applied Financial Economics, 6, 287-292.

Cotton, M. (1990). Value betting. London: Aesculus Press.

Crafts, N. F. R. (1985). Some evidence of insider knowledge in horse race betting in Britain. Economica, 52, $295-304$.

Doerner, D. (1980). On the problems people have in dealing with complexity. Simulation and Games,11, 87-106.

Dowie, J. (1976). On the efficiency and equity of betting markets. Economica, 43, 139-150.

Dror, I. E., Busemeyer, J., \& Basola, B. (1999). Risk taking under time pressure: An independent test of sequential sampling models. Memory and Cognition, 27, 713-725.

Dror, I. E., \& Charlton, D. (2006). Why experts make errors. Journal of Forensic Identification, 56, $600-616$.

Dror, I. E., Kosslyn, S. M., \& Waag, W. (1993). Visual-spatial abilities of pilots. Journal of Applied Psychology, 78, 763773.

Dror, I. E., \& Rosenthal, R. (2008). Meta-analytically quantifying the reliability and biasability of forensic experts. Journal of Forensic Sciences, 53, 900-903.

Duncan, D. (1989). Betting for profit. London: Foulsham.

Eiser, J. R., \& van der Pligt, J. (1988). Attitudes and decisions. London: Routledge.

Figlewski, S. (1979). Subjective information and market efficiency in a betting market. Journal of Political Economy, 87, 75-89.

Fox, C. R., Brett, A., Rogers, B. A., \& Tversky, A. (1996). Options traders exhibit subadditive decision weights. Journal of Risk and Uncertainty, 13, 5-17.

Gander, J. M., Zuber, R. A., \& Johnson, R. S. (2001). Searching for the favourite-longshot bias down under: An examination of the New Zealand pari-mutuel betting market. Applied Economics, 33, 1621-1629.

Gramm, M. K., \& Owens, D. H. (2006). Efficiency in pari-mutuel betting markets across wagering pools in the simulcast era. Southern Economic Journal, 73, 926-937.

Hall, D. (1994). How to win on the horses. London: Headline Book Publishing. 
Hamid, S. S., Prakash, A. J., \& Smyser, M. W. (1996). Marginal risk aversion and preferences in a betting market. Applied Economics, 28, 371-376.

Henery, R. J. (1985). On the average probability of losing bets on horses with given starting price odds. Journal of the Royal Statistical Society. Series A (General), 148, 342-349.

Hogarth, R. M. (1975). Decision time as a function of task complexity. In D. Wendt, \& C. Vlek (Eds.), Utility, probability and human decision making (pp. 321-338). Dordrecht, Holland: Reidel Publishing Co.

Jacoby, J., Speller, D. E., \& Berning, C. K. (1975). Brand choice behavior as a function of information load: Replication and extension. Journal of Consumer Research, 1, 33-42.

Jacoby, J., Speller, D. E., \& Kohn, C. A. (1974). Brand choice behavior as a function of information load. Journal of Marketing Research, 11, 62-69.

Johnson, J. E. V., \& Bruce, A. C. (1997). A probit model for estimating the effect of complexity on risk taking. Psychological Reports, 80, 763-772.

Johnson, J. E. V., \& Bruce, A. C. (1998). Risk strategy under task complexity: A multivariate analysis of behavior in a naturalistic setting. Journal of Behavioral Decision Making, 11, 1-18.

Johnson, J. E. V., \& Bruce, A. C. (2001). Calibration of subjective probability judgments in a naturalistic setting. Journal of Organizational Behavior and Human Decision Processes, 85, 265-290.

Kahneman, D., Slovic, P., \& Tversky, A. (1982). Judgment under uncertainty: Heuristics and biases. New York: Cambridge University Press.

Kahneman, D., \& Tversky, A. (1979). Prospect theory: An analysis of decisions under risk. Econometrica, 47, $263-291$.

Keren, G., \& Wagenaar, W. A. (1985). On the psychology of playing blackjack: Normative and descriptive considerations with implications for decision theory. Journal of Experimental Psychology: General, 114, 133-158.

Klein, N. M., \& Yadav, M. S. (1989). Context effects on effort and accuracy in choice: An enquiry into adaptive decision making. Journal of Consumer Research, 15, 411-421.

Law, D., \& Peel, D. A. (2002). Insider trading, herding behaviour and market plungers in the British horse-race betting market. Economica, 69, 327-338.

Levitt, S. D. (2004). Why are gambling markets organised so differently from financial markets? Economic Journal, 114, $223-246$.

Malhotra, N. K. (1982). Information load and consumer decision making. Journal of Consumer Research, 8, 419-430.

McFadden, D. (1974). Conditional logit analysis of qualitative choice behaviour. In P. Zarembka (Ed.), Frontiers in econometrics (pp. 105-142). New York: Academic Press.

McGlothlin, W. H. (1956). Stability of choices among uncertain alternatives. American Journal of Psychology, 69, 604619.

Mordin, N. (1992). Betting for a living. Oswestry, UK: Aesculus Press.

Onken, J., Hastie, R., \& Revelle, W. (1985). Individual differences in the use of simplification strategies in a complex decision-making task. Journal of Experimental Psychology: Human Perception and Performance, 11, 14-27.

Paquette, L., \& Kida, T. (1988). The effect of decision strategy and task complexity on decision performance. Organizational Behavior and Human Decision Processes, 41, 128-142.

Payne, J. W., Bettman, J. R., \& Johnson, E. J. (1993). Adaptive decision making. Cambridge: Cambridge University Press.

Quandt, R. E. (1986). Betting and equilibrium. Quarterly Journal of Economics, 101, 201-207.

Reason, J. L. (1990). Human Error. Cambridge: Cambridge University Press.

Ritov, I., \& Baron, J. (1990). Reluctance to vaccinate: Omission bias and ambiguity. Journal of Behavioral Decision Making, 3, 263-277.

Rottenstreich, Y., \& Tversky, A. (1997). Unpacking, repacking, and anchoring: Advances in support theory. Psychological Review, 104, 406-415.

Rumelhart, D., \& Greeno, J. (1971). Similarity between stimuli: An experimental test of the Luce and Restel choice model. Journal of Mathematical Psychology, 8, 370-381.

Shin, H. S. (1991). Optimal betting odds against insider traders. Economic Journal, 101, 1179-1185.

Shin, H. S. (1992). Prices of state contingent claims with insider traders, and the favourite-longshot bias. Economic Journal, 102, 426-435.

Shin, H. S. (1993). Measuring the incidence of insider trading in a market for state-contingent claims. Economic Journal, 103, 1141-1153.

Smith, M. D., Paton, D., \& Vaughan Williams, L. (2006). Market efficiency in person-to-person betting. Economica, 73, 673-689.

Snowberg, E., \& Wolfers, J. (2005). Explaining the favorite-longshot bias: Is it risk-love, or misperceptions? Mimeo, University of Pennsylvania.

Snyder, W. W. (1978). Horse racing: Testing the efficient markets model. Journal of Finance, XXXIII, 1109-1118. 
Sundstroem, G. A. (1989). Information search and decision-making: The effects of information displays. In H. Montgomery, \& O. Svenson (Eds.), Process and structure in human decision-making. London: Wiley. $209-224$.

Sung, M.-C., \& Johnson, J. E. V. (2007). The influence of market ecology on market efficiency: Evidence from a speculative financial market. Journal of Gambling, Business and Economics, 1, 185-198.

Sung, M.-C., \& Johnson, J. E. V. (2008). Revealing weak form efficiency in a market for state contingent claims. Economica, (in press).

Terrell, D., \& Farmer, A. (1996). Optimal betting and efficiency in pari-mutuel betting markets with information costs. Economic Journal, 106, 846-868.

Thaler, R. H., \& Ziemba, W. T. (1988). Anomalies: Pari-mutuel betting markets: Racetracks and lotteries. The Journal of Economic Perspectives, 2, 161-174.

Timmermans, D. (1993). The impact of task complexity on information use in multi-attribute decision making. Journal of Behavioral Decision Making, 6, 95-111.

Tuckwell, R. H. (1983). The thoroughbred gambling market: Efficiency, equity and related issues. Australian Economic Papers, June, 106-118.

Tversky, A. (1972). Elimination by aspects: A theory of choice. Psychological Review, 79, 281-199.

van Zijl, T. (1984). Returns and weak form efficiency: Betting markets. Working Paper, Victoria University of Wellington.

Vaughan Williams, L., \& Paton, D. (1997). Why is there a favourite longshot bias in British racetrack betting markets? Economic Journal, 107, 150-158.

Vaughan Williams, L., \& Paton, D. (1998). Why are some favourite-longshot biases positive and others negative? Applied Economics, 30, 1505-1510.

Walls, W. D., \& Busche, K. (2003). Breakage, turnover, and betting market efficiency: New evidence from Japanese horse tracks. In L. Vaughan Williams (Ed.), The economics of gambling (pp. 43-66). London: Routledge Taylor \& Francis Group.

Weitzman, M. (1965). Utility analysis and group behavior: An empirical study. Journal of Political Economy, 73, $18-26$.

Wilde, G. J. S. (1988). Risk homeostasis theory and traffic accidents: Propositions, deductions and discussion of dissention in recent reactions. Ergonomics, 31, 441-468.

Wright, P. (1975). Consumer choice strategies: Simplifying vs. optimizing. Journal of Marketing Research, $11,60-67$.

Ziemba, W. T., \& Hausch, D. B. (1986). Betting at the racetrack. Los Angeles: Dr. Z. Investments Ltd.

\section{Authors' biographies:}

M.-C. Sung is Lecturer in Management Science in the School of Management at the University of Southampton, UK. Her research focuses on behavioral finance, financial econometrics, and the application of Data Mining for decision-making in markets for state contingent claims. Other recent projects relate to prediction markets and behavioural economics. She has presented her research at a number of leading international conferences, and has published her work in a wide range of journals in economics, operations research, and decision-making.

J. E. V. Johnson is Professor of Decision and Risk Analysis and Director of the Centre for Risk Research in the School of Management at the University of Southampton, UK. His research focuses on risk perception, risk taking and decisionmaking in speculative markets.

I. E. Dror (PhD Harvard) is a Senior Lecturer in the School of Psychology at the University of Southampton, UK. As a cognitive neuroscientist, he investigates how internal and external factors, along with the decision problem itself, come together in decision making. He examines time pressure, risk taking, and biases, and ways to improve real world decisions within forensic, military, and the financial domains.

Authors' address:

M.-C. Sung, Centre for Risk Research, School of Management, University of Southampton, Highfield, Southampton, SO17 1BJ, UK.

J. E. V. Johnson, Centre for Risk Research, School of Management, University of Southampton, Highfield, Southampton, SO17 1BJ, UK.

I. E. Dror, School of Psychology, University of Southampton, Highfield, Southampton, SO17 1BJ, UK. 